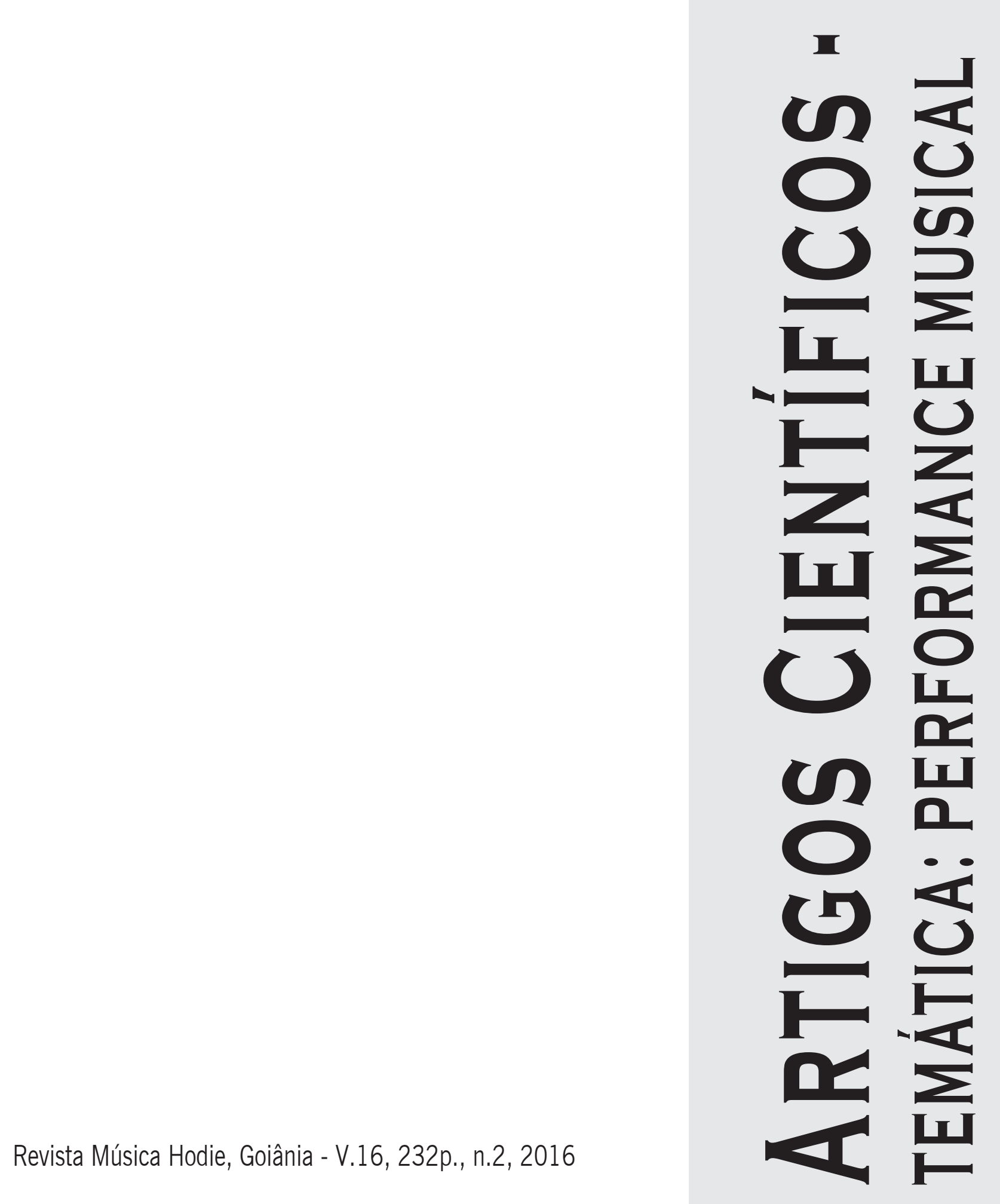




\title{
Sugestões para a preparação de excertos orquestrais do romantismo para viola
}

\author{
Luciano Pontes (EMAC/Universidade Federal de Goiás, Goiânia, Goiás, Brasil)
}

luc_pontes@yahoo.com.br

\begin{abstract}
Resumo: Este artigo propõe algumas estratégias de preparação para excertos orquestrais de obras escritas para viola. Foram realizadas análises de aspectos técnicos do instrumento em três excertos relevantes do período romântico, utilizando como fundamentação importantes aspectos de trabalhos escritos por autores como Flesh, Ficher, Brandolino, Yost entre outros. O objetivo principal é sugerir alternativas de estudo que possam orientar o violista a organizar sua preparação de excertos, a fim de otimizar seu desempenho em concursos, provas de banca e performances em geral. Observamos que a preparação de excertos do violista a fim de obter sucesso em audições orquestrais possui vários desafios, desde tocar com uma boa afinação a sensibilidade de lidar com diversidades estilísticas que compõem o repertório de uma audição. Verificamos a necessidade da elaboração de um planejamento estratégico de estudo direcionado para solucionar casuais problemas que podem surgir ao longo da preparação. Esperamos que este artigo contribua com a pesquisa e ensino da viola no Brasil.
\end{abstract}

Palavras-chave: Viola; Excertos orquestrais; Repertório romântico.

Suggestions for orchestral excerpts preparation of romanticism for viola

Abstract: This article proposes some study strategies of preparation for viola orchestral excerpts of works written for viola. Analyses were accomplished of technical aspects of the instrument in three essential excerpts from the romantic period utilizing as substantiation important aspects of search written by authors as Flesh, Ficher, Brandolino, Yost and others. The main objective was to propose study alternatives that can help the violist to organize your excerpts preparation, in order to optimize their practice in competition, test with board of examining and performances in general. Noted that the excerpts preparation of violist, in order to get successful in orchestral auditions, has many challenges, since to play with a good intonation to sensibility to deal with stylistic differences that make up the repertoire of a audition. Verified the preparing necessity of strategic planning study directing to solve casual problems that can emerge during the preparation. Hoped this article contribute with the research and viola teach in Brasil.

Keywords: Viola; Orchestral excerpts; Romantic repertoire.

Sugerencias para la preparación de fragmentos orquestrales de lo romanticismo para viola

Resumen: Este artículo propone algunas estrategias para la preparación de fragmentos orquestales de obras escritas para viola. Se llevaron a cabo análisis de los aspectos técnicos de lo instrumento en tres extractos relevantes de la época romántica, utilizando como fundamentación aspectos importantes de las obras escritas por autores tales como, Fischer, Brandolino, Yost y otros. El principal objetivo es sugerir posibilidades de estudio que pueden guiar el violista a organizar la preparación de los fragmentos con el finalidad de optimizar su rendimiento en las competiciones, audiciones y en las actuaciones en general. Observamos que la preparación de fragmentos de lo violista con el fin de tener éxito en las audiciones de orquesta tiene varios retos, desde jugar con una buena entonación a la sensibilidad para manejar diferencias de estilo que componen el repertorio de una audición. Hemos identificado la necesidad de desarrollar un estudio de planificación estratégica destinada a resolver los problemas ocasionales que puedan surgir durante la preparación. Esperamos que este artículo va a contribuir a la investigación y la enseñanza de la viola en Brasil.

Palabras clave: Viola; Fragmentos orquestales; Repertorio romântico.

Excertos orquestrais tem sido requeridos cada vez mais frequentemente em audições de orquestras e festivais de música, sendo esta, uma das formas mais utilizadas em seleções para atestar a condição técnica musical dos candidatos. Romanov (2009, p. 11) observa que a grande ocupação dos profissionais da música com a preparação de recitais, aulas, performances em orquestras, grupos de câmara, entre outros, restringe os períodos de tempo para a preparação de uma performance pública que, geralmente, exige "do músico competência, concentração e aproveitamento". Cita ainda que "a dificuldade no treinamento dos músicos está ligada a habilidade de estudar eficientemente” (p. 11).

Partindo desta reflexão, este artigo propõe através de uma análise voltada para alguns dos aspectos específicos da linguagem do instrumento, algumas alternativas de es- 
tudo que possam orientar o violista na preparação de trechos específicos extraídos de três excertos orquestrais. Os excertos selecionados são: O Scherzo da obra A Midsummer Nights Dream de Mendessohn, primeiro movimento da Sinfonia No. 2 in D Major, Op. 73 de Brahms e Dom Juan, op. 20 de R. Strauss. Pretende-se basear em alguns fundamentos propostos por autores como Fischer (2001), entre outros, a fim de propor ideias para soluções de problemas contidos nestas obras.

SILVA (2010, p. 20) observa que no século XIX, a viola começa a ganhar notoriedade no repértório sinfônico e camerístico, apesar de ainda não ocupar um lugar de destaque como instrumento solista. Relata ainda que na primeira metade do século XIX, surgem vários livros de estudo publicados para viola, sendo influenciados de certa forma, por vários violinistas virtuosos e também pelo surgimento de inúmeros musicistas amadores. Nesta época, surgem com mais frequência repertórios abrangendo aspectos violísticos como cordas duplas, triplas e quadruplas, spiccato, entre outros, como por exemplo o compositor Casimir Ney (1801-1877) que compôs 24 Preludios para viola solo considerados de grande dificuldade, incluindo passagens com intervalos de décimas, harmônicos duplos, sautillé, pizzicato de mão esquerda, além de explorar toda a extensão do instrumento.

Os excertos foram escolhidos objetivando reunir trechos que contemplassem aspectos como spiccato, trocas de cordas, precisão rítmica, afinação, legato e velocidade da mão esquerda. Pretende-se, através desta pesquisa, auxiliar violistas na preparação efetiva destes trechos, bem como incentivar a utilização de excertos nos estudos de técnica básica.

São muitos os elementos que compõe o estudo diário de técnica básica do estudante de viola, tais como: arpejos, cordas duplas, escalas, golpes de arcos como martelé, detaché, spiccato, collé, entre outros, sendo estes fundamentos, alguns dos desafios voltados para a técnica básica do instrumento. Faz-se necessário salientar, que alguns destes fundamentos são estudados a partir de transcrições de estudos escritos originalmente para violino.

SILVA (2010, p. 32) observa que a partir do início do século XX, começam a surgir com mais frequência, materiais publicados especificamente para viola, que contribuem significativamente para a pedagogia e performance do instrumento. Salienta ainda (p. 31), que havia considerável familiarização de violistas com métodos de estudos escritos originalmente para violino, destacando-se alguns dos inúmeros autores de métodos escritos primariamente ou transcritos para viola: Kreutzer, Hoffmeister, Bruni, Campagnoni, Rode, entre outros. Apesar destas questões discutidas, consideraremos algumas diferenças relevantes entre estes instrumentos.

KUBALA apud REBELLO (2011, p. 68) cita a emissão de som da viola, como uma diferença relevante em relação ao violino, exigindo do instrumentista o uso mais constante do peso do braço e antebraço, bem como maior firmeza ao segurar o arco em relação ao violino. Relata ainda que, geralmente, os violistas tocam com o arco mais próximo ao talão em relação ao violino, pelo fato do arco ser um pouco mais pesado e consequentemente favorecer a utilização do peso do braço com mais frequência. Um dos aspectos que demonstram maior diferença entre os dois instrumentos é o vibrato, sendo que devido ao comprimento maior da corda e consequentemente os dedos ficarem mais afastados sobre o espelho, "o violista necessita ter um vibrato mais longo para que as oscilações sejam audíveis", afirma Rebello (2011, p. 72).

Apesar de haverem diferenças entre os dois instrumentos, procuraremos nos apoiarem alguns conceitos publicados originalmente para violino, como FISCHER (2001) por exemplo, pois, entendemos ser utilizáveis para preparação dos excertos aqui selecionados, por abrangerem aspectos técnicos que consideramos comuns aos dois instrumentos. 
Faz-se necessário esclarecer, que existem inúmeras formas e métodos para a preparação de excertos. Proporemos a seguir algumas sugestões que consideramos importantes para o planejamento de estudo dos trechos discutidos a seguir.

\section{Aspectos técnicos na preparação dos excertos}

A seguir, sugeriremos algumas alternativas de preparação para três excertos relevantes do período romântico, objetivando fornecer subsídios de estudo que possam orientar o violista na preparação dos trechos aqui selecionados.

\subsection{A Midsummer Nights Dream de Felix Mendelsshon}

Entre os inúmeros aspectos perceptíveis neste excerto, destacamos a necessidade de uma boa precisão rítmica, atenção com a dinâmica, além de executar as trocas de cordas com clareza. A peça apresenta, entre o compasso 1 e 93 do Scherzo, um caráter leggiero e animado, com pequenos crescendos que não ultrapassam a dinâmica em piano.

Por se tratar de um excerto, com o caráter aqui citado, bem como o rítmico contínuo, manter a execução do spiccato com precisão e clareza torna-se um desafio. O exercício abaixo proposto, sugere ao violista estudar em cordas soltas, os compassos entre 60 e 63, isolando a mão esquerda, a fim de concentrar-se apenas no spiccato. Acredita-se que este exercício pode proporcionar mais foco do violista em relação as mudanças de corda.

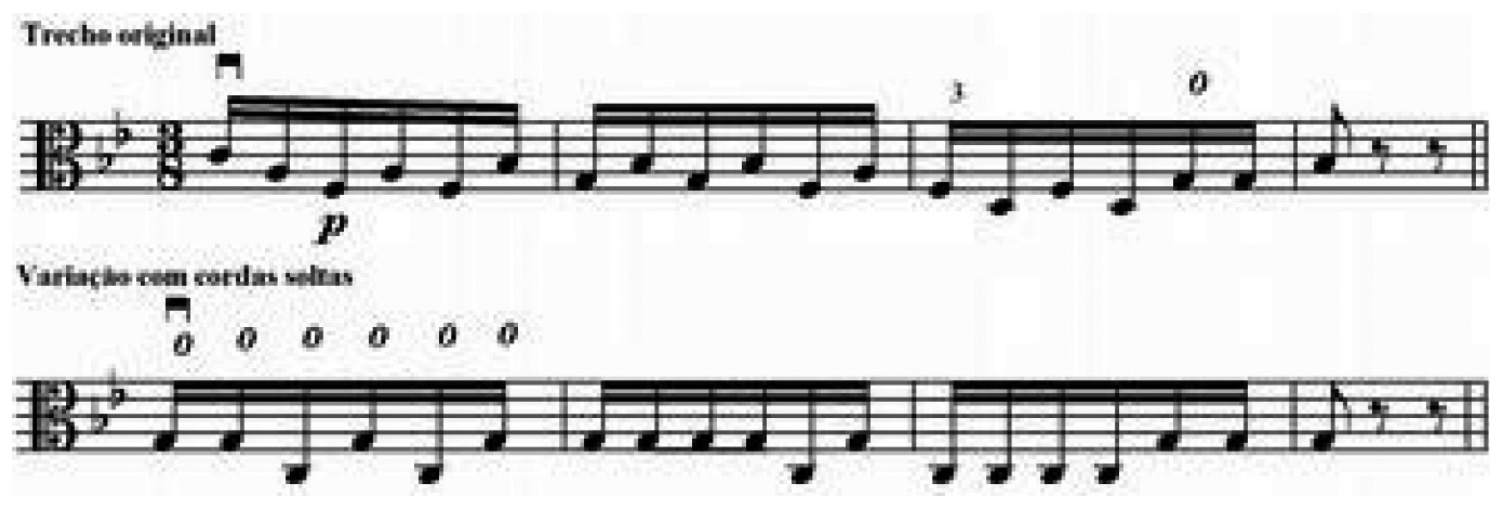

Exemplo 1: F. Mendelsshon - A Midsummer Nights Dream, Scherzo, c. 60.

Sobre o estudo de passagens com padrões rítmicos, Ficher apud Reinert (2007, p. 60) observa que se deve considerar também a afinação de cada nota, a qualidade do som pura, rítmos precisos e constantes, e mesmo com a aplicação dos padrões rítmicos, a performance da passagem precisa aparentar ser de fácil execução. Aplicar variações rítmicas entre a anacruse do compasso 75 ao compasso 79, pode melhorar a coordenação entre as mãos, pois, quando se aplicam variações em um determinado trecho, há uma mudança no ritmo das notas, além de proporcionar uma sonoridade mais clara principalmente nas troca de arco, conforme relata Chang (2014, p. 15). Reinert (2007, p. 58) observa que esta modalidade de prática permite "que o intérprete desenvolva uma figura mental da passagem - e, como resultado desse processo, obtém-se a conscientização rítmica”. Existem inúmeras formas de padrões rítmicos, a seguir citaremos somente algumas que julgamos importantes para aplicação no trecho aqui discutido. 

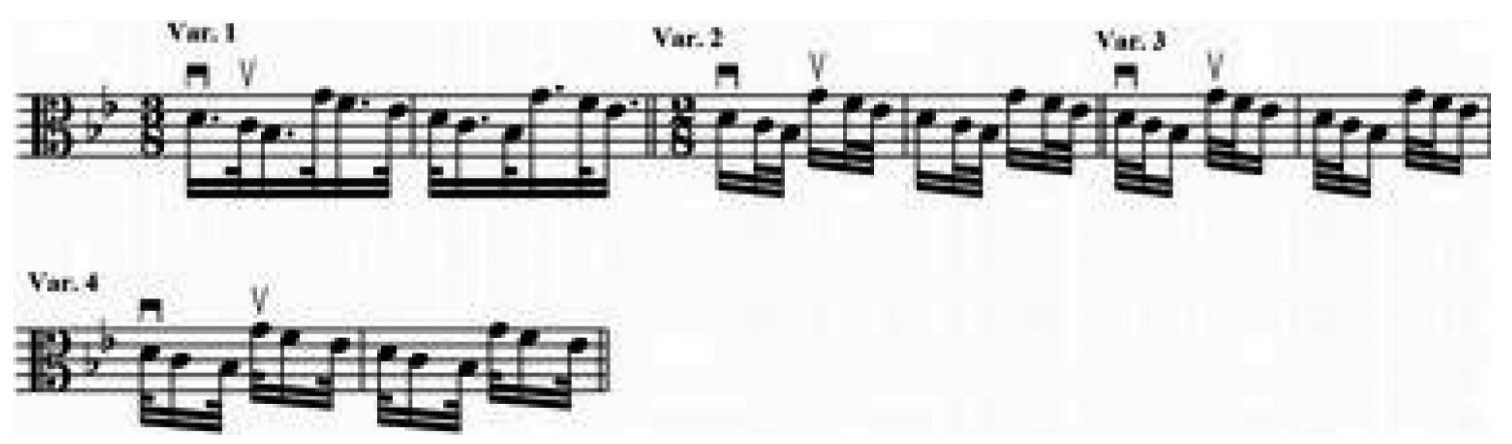

Exemplo 2: F. Mendelsshon - A Midsummer Nights Dream, Scherzo, c. 75.

\subsection{Sinfonia n. 02, Op. 73 de Johannes Brahms}

Entre os desafios para a preparação presentes neste excerto, destacamos a precisão rítmica necessária requerida. Para se obter as articulações rítmicas de forma mais precisas, sugere-se subdividir a passagem em semicolcheias, objetivando entender a exata posição de cada figura rítmica dentro do tempo. Chang (2014, p. 50), quando analisa a parte de primeiro violino deste mesmo excerto, sugere o estudo desta subdivisão com dois violinistas, onde o primeiro toca o tema principal e o outro toca o padrão de variação abaixo, utilizando a nota $\mathrm{Mi}$, pois isto ajudaria o violinista que toca o tema original na manutenção do ritmo.
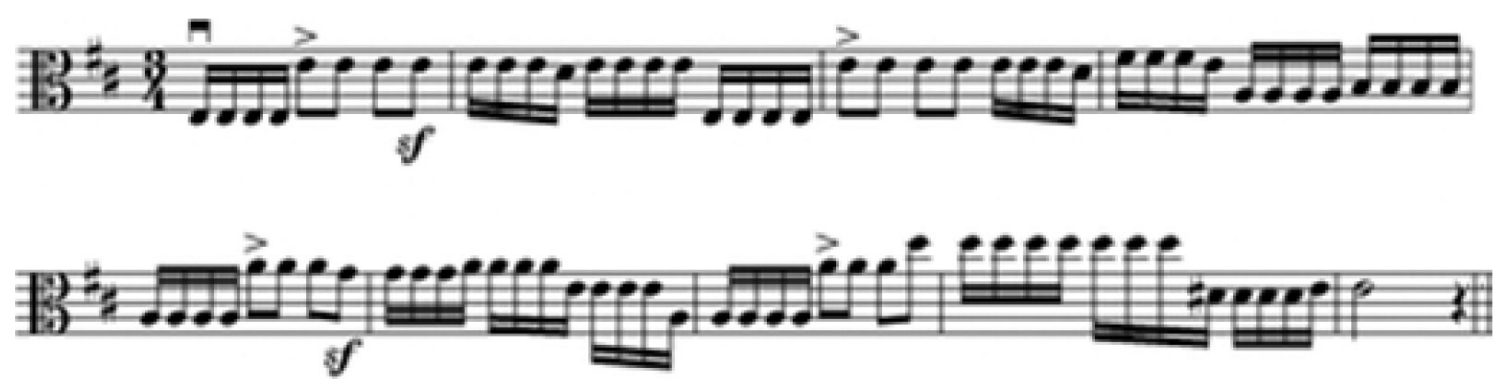

Exemplo 3: J. Brahms - Sinfonia No. 2 in D Major, Op. 73, mov. I, c. 118.

O exercício a seguir pode auxiliar o violista no estudo isolado do movimento circular da mão direita durante as retomadas de arco constantes nesta passagem. Sugere-se estudar em andamentos mais lentos, objetivando trabalhar a antecipação do contato do arco sobre a corda antes da emissão do som, além de favorecer a busca por melhor precisão rítmica.

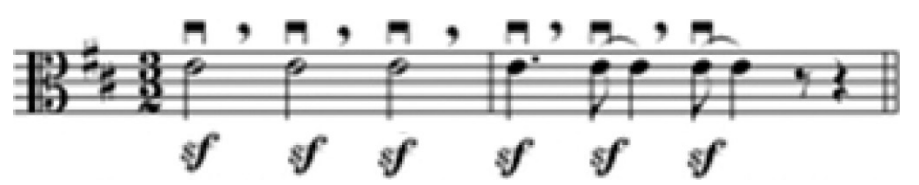

Exemplo 4: J. Brahms - Sinfonia No. 2 in D Major, Op. 73, mov. I, c. 118. 


\subsection{Don Juan, op. 20 de Richard Strauss}

Entre os inúmeros desafios técnicos que caracterizam este excerto, destacam-se neste artigo, a afinação, rapidez da mão esquerda e legato em passagens rápidas. Sugere-se, no compasso 06, o estudo da passagem em pequenos agrupamentos de notas organizados de acordo com as mudanças de corda, com interrupções sempre que houverem trocas de cordas. Acredita-se que praticar este trecho desta forma, pode ajudar o violista a obter melhor consciência sobre a antecipação necessária do braço e ante braço direito antes de cada alternância de corda, bem como obter mais segurança na mão esquerda ao se estudar cada dedilhado, separadamente, e em cada corda correspondente, conforme o exemplo a seguir.

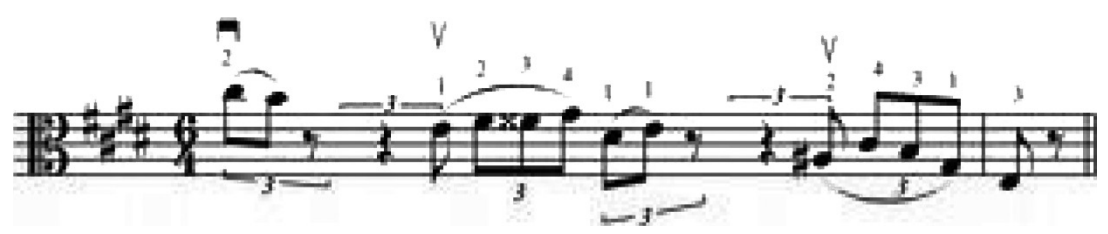

Exemplo 5: R. Strauss - Don Juan op. 20, c. 06.

A afinação constitui-se como um grande desafio neste excerto, pois o violista lida com mudanças de posições em passagens com andamento rápido, e as vezes em cromatismo. Sugere-se estudar a passagem entre o compasso 23 e 26 em andamento lento, procurando concentrar a audição na afinação e a mão direita na extração de uma sonoridade clara que possibilite ao violista ouvir a real afinação produzida. "O músico que estuda lentamente possui maior grau de conscientização muscular, melhor memória, mais autocontrole e coragem do que quem estuda rápido”, conforme cita Flesch (1930 apud ANDRADE NETO 2010, p. 18). Posteriormente, o violista deve acelerar gradualmente o andamento do trecho, a fim de aproximar-se do tempo final requerido. FLESCH (1989) propõe no seu Escales System, aplicar vibrato no estudo para afinação apenas quando os problemas mais críticos de entonação estiverem resolvidos.

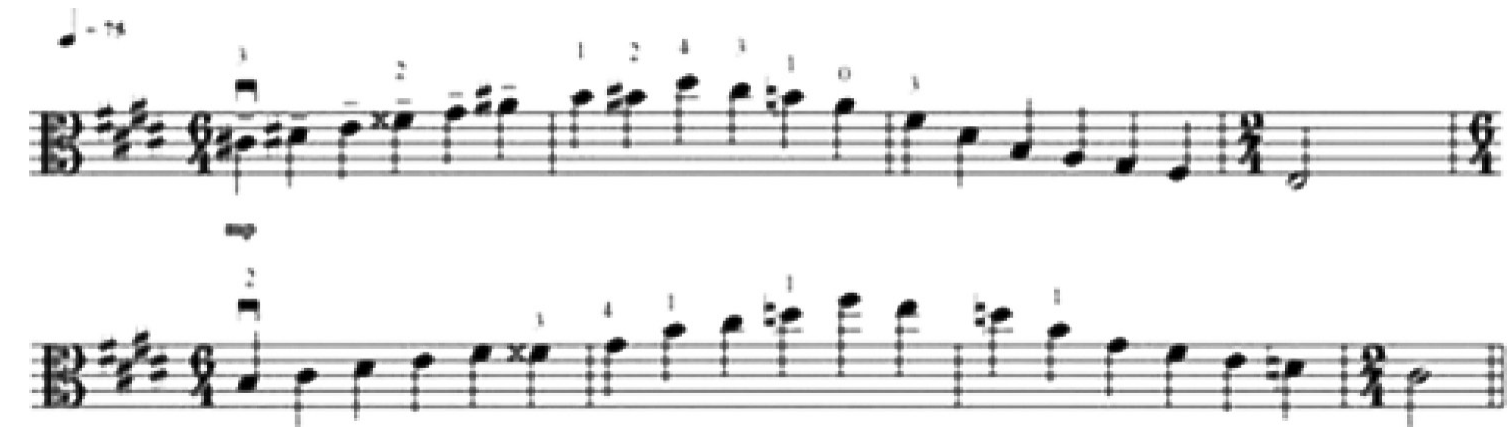

Exemplo 6: R. Strauss - Don Juan, op. 20, c. 23.

Sugere-se, na passagem a partir do c. 33, o estudo com a extração de determinadas notas, favorecendo a escuta específica de algumas notas, possibilitando maior concentração na afinação. Aconselha-se estudar, principalmente as variações II, III e IV, pensando na relação intervalar entre as notas, possibilitando ao violista construir auditivamente, a estrutura melódica da passagem, bem como sua memorização. 

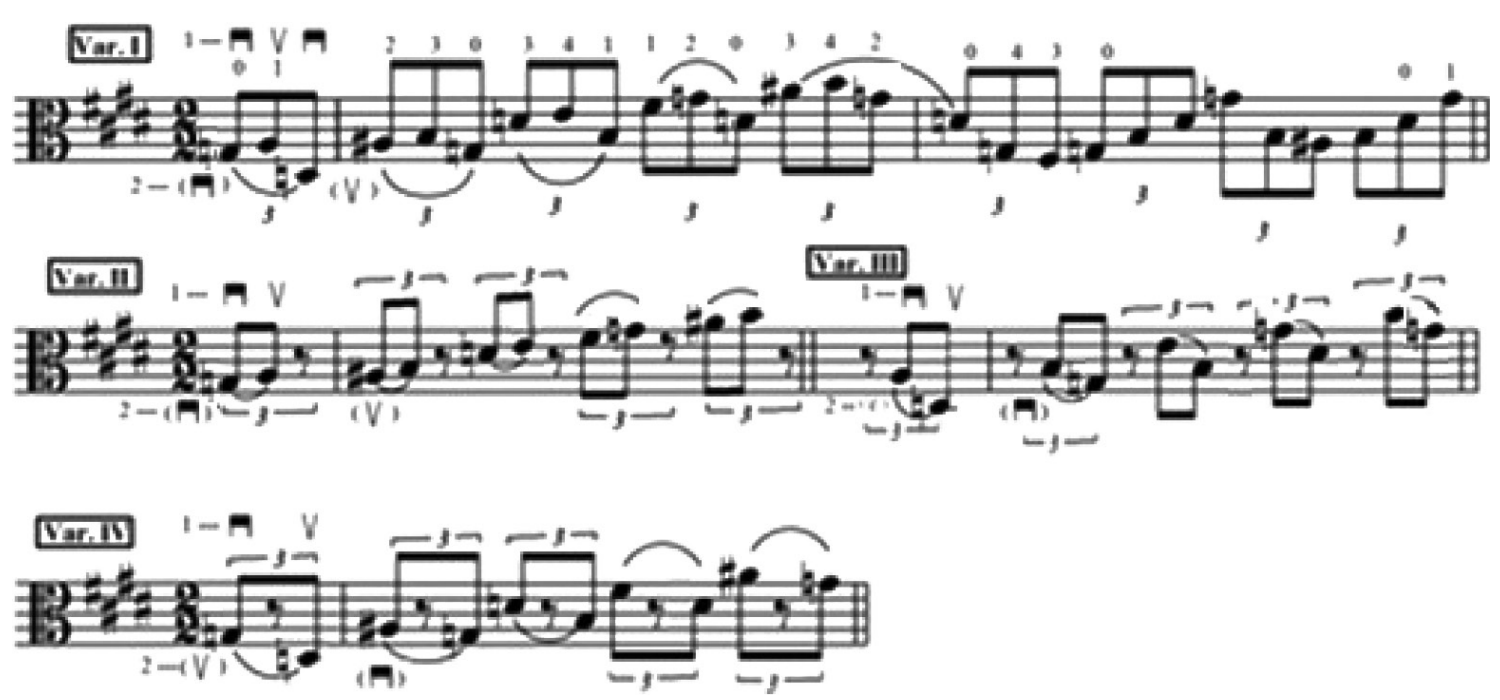

Exemplo 7: R. STRAUSS - Don Juan, op. 20, c. 33.

No compasso 25, recomenda-se agrupar o dedilhado em blocos, propiciando assim, maior domínio nas mudanças de posições e consequentemente durante cada posição exigida durante a passagem. As mudanças de posição devem ser realizadas da seguinte forma: primeiro tocar as mudanças de forma antecipada (durante as pausas), posteriormente interromper o som especialmente nas pausas e realizar apenas o movimento físico da mudança de posição, e por último encurtar cada vez mais a duração da pausa até tocar a passagem conforme o texto original. Este processo deve ser realizado em vários andamentos até o violista alcançar o andamento final da passagem. YOST (1928, p. 2) observa que mudanças de posição devem ser estudadas lentamente e repetidas muitas vezes, não pressionando o polegar contra o braço do instrumento e não apertando os dedos sobre as cordas durante o deslizar dos dedos nas mudanças de posição.

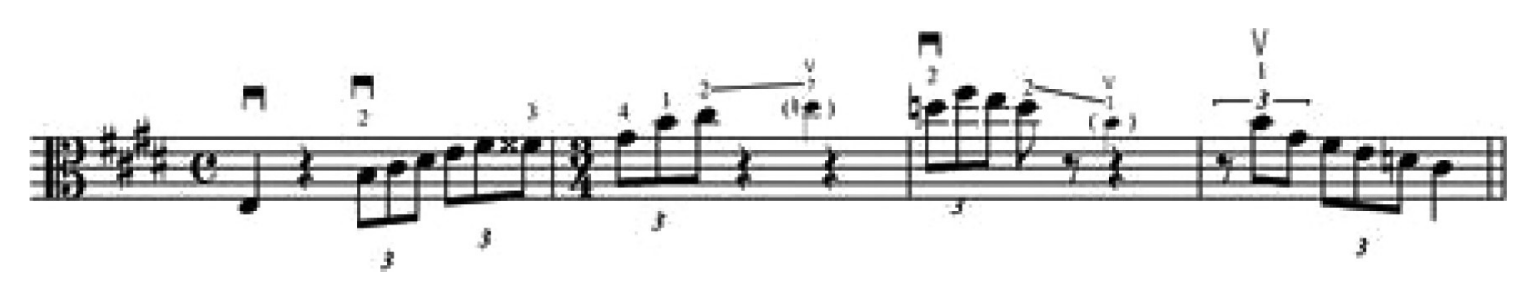

Exemplo 8: R. Strauss - Don Juan, op. 20, c. 25.

FISCHER (2001, p. 7), discutindo a preparação de passagens em andamentos velozes, aborda sobre a técnica de dedos rápidos, que consiste em deixar os dedos da mão esquerda caírem e levantarem de sobre o espelho mui rapidamente, gerando mais velocidade e solidez. Romanov (2011, p. 34) ressalva que esta técnica propicia "movimentos mais leves e precisos, sem aplicar pressão excessiva, o que, com certeza, facilita toda a técnica da mão esquerda no andamento rápido”. Concordando com FICHER (2001), uma boa coordenação consiste em posicionar os dedos da mão esquerda de forma antecipada ao movimento do arco, de maneira que os dedos desta mão exerçam liderança sobre o arco.

Sugere-se estudar esta passagem, primeiramente sem o arco, utilizando a técnica de dedos rápidos, levantando os dedos e deixando-os cair firmemente com elasticidade sempre que possível, conforme o exemplo a seguir, do c. 52. 


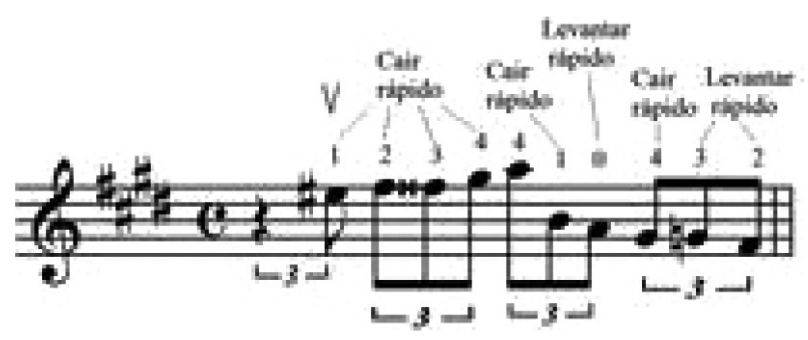

Exemplo 9: R. Strauss - Don Juan, op. 20, c. 52.

\section{Considerações finais}

A partir das análises e sugestões postas neste artigo, foi possível perceber que são muitos os desafios do violista a fim de se obter sucesso em uma audição para a admissão de novos músicos em uma orquestra, destacando-se: tocar com uma boa afinação, apresentar boa precisão rítmica, demonstrar sólida ambientação com a instrumentação e estilo, destreza na variação dos contrastes de dinâmica, apresentação com clareza as instruções do compositor contidas no texto musical, habilidade de tocar em conjunto com outros músicos e a sensibilidade de lidar com a diversidade estilística que compõe o repertório de uma audição.

Considera-se primordial a elaboração de um planejamento de estudo voltado para as soluções dos eventuais problemas que surgirão no decorrer da preparação, sendo necessário, após uma primeira leitura do excerto, a realização de uma análise com o objetivo de identificar os principais desafios, e a partir de então, o isolamento dos trechos que apresentam mais dificuldade.

Ter acesso a várias gravações pode amparar o violista a ter plena noção do estilo da obra e dos tipos de articulações e arcos peculiares a cada compositor. Tocar o trecho juntamente a uma boa gravação pode auxiliar o violinista na ambientação com a instrumentação que abrange determinada passagem, podendo auxiliá-lo a identificar possíveis falhas com notas e ritmos bem como a ambientação com o caráter estilístico da obra.

O ritmo configura-se como outro desafio substancial na preparação de excertos do violista, nota-se que muitos instrumentistas direcionam o estudo com metrônomo principalmente a passagens com andamentos rápidos. Sobre este aspecto, BRANDOLINO (1997, p. 20) sugere utilizar o metrônomo não apenas em trechos que apresentam mais dificuldade rítmica, mas também com a finalidade de alcançar o tempo apropriado para cada trecho orquestral.

Outro fator a ser observado no repertório de excertos do violista é a presença de muitos trechos que não são considerados linhas melódicas. Sobre esta característica, MCCARTY (1988, p. 4) sugere que o instrumentista não se preocupe apenas com aspectos como ritmo, tempo e notas exatas, mas também com questões como contornos de frases, cores tímbricas dentro de determinadas dinâmicas, tensões harmônicas distribuídas dentro do excerto, entre outras. Observa-se, neste contexto, a necessidade de entendimento do violista em relação a partitura de regência, objetivando buscar maior familiarização com os diversos aspectos que compõe o trecho a ser preparado.

Entende-se que tocar excertos com uma afinação satisfatória em audições, configura-se também como um dos notáveis desafios para o violista. Sugere-se o estudo de excertos em andamentos lentos e sem vibrato, afim de que o violista perceba com mais clareza a real afinação que ele está produzindo, sendo que o vibrato deve ser utilizado como um recurso expressivo, e adaptado conforme as condições de intensidade e caráter presentes ao longo do excerto. 


\section{Referências}

ANDRADE NETO, Silas de. O Estudo Diário do Violino: uma investigação da rotina de preparação técno-interpretativa dos alunos do Curso de Bacharelado em Música da FAMES. Dissertação de Mestrado. Escola de Música da Universidade Federal de Minas Gerais, 2010. Belo Horizonte: UFMG, 2010. 53 p.

BRAHMS, Johanes. Symphony No. 2 in D Major, Op. 73. New York: Kalmus. 1933.

BRANDOLINO, L. A. A Study of Orchestral Audition Repertoire for Violin. Tese de Doutorado. Music Conservatory of the University of Missouri, 1997. Kansas: MU, 1997. 203 p.

CHANG, Ai-Wei. Utilizing Standard Violin Orchestral Excerpts as a Pedagogical Tool: an analytical sudy guide with functional exercises. Tese de Doutorado. College of Music of the University of North Texas, 2014. Denton: UT, 2014. 83 p.

CHEN, Yu-Fang. Pedagogical Literatura for Violists: selected studies from lilianfuchs's 16 fantasy études and corresponding orchestral audition excerpts. Tese de Doutorado. Music Conservatory of the University of Missouri, 2013, Kansas: MU, 2013. 100 p.

FISCHER, Carl. Practice. London: Edition Peters, 2001.

FLESCH, Carl. The art of violin playing. Artistc realization and insruction. New York: Carl Fischer, 2000.

. Escales System. New York: Carl Fischer, 1987.

GERLE, Robert. The Art of practising the violin. London: Stainer\& Bell, 1983.

MCCARTY, Patrícia. A Preparation Strategy for Successful Orquestral Auditions. Disponível em: <http://www.revisemysite.com/pdfs/-66-audart.pdf>. Acesso em: 15 fev 2014.

MENDELSSHON, Felix. A Midsummer Nights Dream Overture and Incidental Music. New York: Kalmus. 1933.

REBELLO, Ana Isabel Ferreira. Semelhanças e Disparidades no Ensino e na Execução da Viola e do Violino. Dissertação de Mestrado. Escola de Comunicação e Artes da Universidade de São Paulo, 2011. São Paulo: USP, 2011. 137 p.

REINERT, Gina. Fantasia de Concerto Para Violino e Orquestra de Octávio Meneleu Campos: uma propósta pedagógica. Dissertação de Mestrado. Instituto de Artes da Universidade Federal do Rio Grande do Sul, 2007. Porto Alegre: UFRG, 2007. 103 p.

ROMANOV, Elena. Scherzo-Tarantella de Henrik Wieniawski: um plano de estudo. Dissertação de Mestrado. Instituto de Artes da Universidade Federal do Rio Grande do Sul, 2009. Porto Alegre: UFRG, 2009. 82p.

SILVA, Ulisses Carvalho da. Original and Transcribed Etude Books for Viola: a reference guide for teachers and students. Tese de Doutorado. Hugh Hodgson School of Music of the University of Georgia, 2010.Atens: UGA, 2010. 212p.

STRAUSS, Richard. Don Juan, Op. 20. New York: Kalmus, 1933.

YOST, Gaylord. Exercises for change of positions. Pittsburgh: Volkwein Bros., 1928.

Luciano Pontes - Diplomou-se com os títulos de bacharel (2005) e mestre (2012) em música pela Universidade Federal de Goiás. Tem se dedicado a pesquisa voltada para a performance musical e musicologia, bem como ao ensino de Violino, Viola, Música de Câmara e prática de orquestra. Estudou na Academia da OSESP em 2007, e atualmente é violinista concertino da Orquestra do Estado de Mato Grosso, professor de Viola, Música de Câmara e Prática de Orquestra na EMAC-UFG e diretor artístico da Camerata Jean Douliez da mesma instituição. 